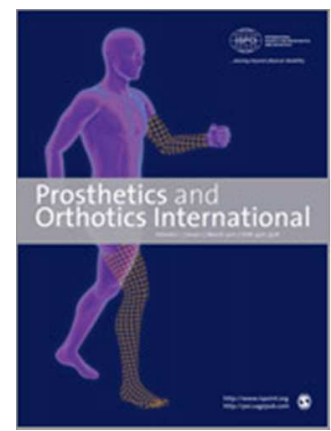

\title{
Dynamic characterisation of Össur Flex-Run Prosthetic feet for a more informed prescription
}

\begin{tabular}{|r|l|}
\hline Journal: & Prosthetics \& Orthotics International \\
\hline Manuscript ID & Draft \\
\hline Manuscript Type: & Original Research Reports \\
\hline Keywords: & $\begin{array}{l}\text { biomechanics of prosthetic/orthotic devices }<\text { biomechanics, Testing of } \\
\text { prosthetic and orthotic components }<\text { biomechanics, prosthetic feet }< \\
\text { prosthetics, prosthetic interface mechanics }<\text { biomechanics }\end{array}$ \\
\hline Author-supplied Keywords: & damping, mode shape, natural frequency, prosthesis \\
\hline & \multicolumn{2}{|l}{} \\
\hline
\end{tabular}


1 Dynamic characterisation of Össur Flex-Run Prosthetic feet for a more

2 informed prescription

3

4 Abstract

5 Background: The current method of prescribing composite Energy Storing and

6 Returning (ESR) feet is subjective and is based only on the amputee's static body

7 weight/mass.

8 Objectives: The aim is to investigate their unique design features through identifying

9 and analysing their dynamic characteristics, utilising modal analysis, to determine

10 their mode shapes, natural damping and natural frequencies. Full understanding of

11 the dynamic characteristics can inform on how to tune a foot to match an amputee's

12 gait and body condition.

13 Methods: This paper presents the modal analysis results of the full range of Össur 14 Flex-Run running feet that are commercially available (1LO-9LO).

15 Results: It is shown that both the undamped natural frequency and stiffness increase 16 linearly from the lowest to highest stiffness category of foot. The effect of over-load 17 and under-loading on natural frequencies is also presented. The damping factor for 18 each foot has been experimentally determined and it was found to be ranging 19 between $1.5-2.0 \%$. An analysis of the mode shapes also showed a unique design 20 feature of these feet that is hypothesised to enhance their performance.

21 Conclusions: A better understanding of the feet dynamic characteristics can help to 22 tune the feet to the user's requirements.

23 (194 words)

25 Clinical relevance 
26 This information is needed in order to better predict how the dynamic data can

27 influence the gait pattern and symmetric transition from walking to running. The data

28 is needed to better understand the role dynamic characteristics of the foot plays

29 when prescribing the prosthesis for walking or running.

30 (48 words)

32 Keywords: damping, dynamic characteristics, modal analysis, mode shape, natural 33 frequency, prosthesis, energy-storing and returning.

35 Background

36 Sport prostheses are used by both upper- and lower-limb amputees while 37 participating in sports and other physical activities. With advances in medicine and 38 an emphasis on maintaining physical fitness, the population of athletes with 39 impairments is growing and receiving great attention 1,2 . This has revealed a 40 considerable shift in the way our culture considers disabilities over the last few 41 decades ${ }^{3,4}$. Until the 1980 s most prosthetic feet were designed with the main 42 objective of restoring basic walking ability and simple occupational tasks ${ }^{5}$. The need 43 for higher performing feet made has led designers to utilise lightweight and more 44 advanced materials such as Carbon Fibre Reinforced Plastic Composite (CFRP).

45 This has resulted in the development of a new generation of energy-storing-and46 returning (ESR) feet, with unique shape and geometrical features. The ESR 47 transforms Potential Energy (PE), into strain energy and returns it back into the body 48 mass in the form of Kinetic Energy (KE) in a short impulses thus helping amputee to 49 accelerate in a forward motion ${ }^{6}$. Their introduction has changed the nature of 
50 amputee sprinting sport. ESR feet are now available in many categories, in terms of

51 their stiffness/performance, catering for most types of recreational activity.

The energy efficiency of ESR feet varies between different suppliers. Their energy return rates have been found to range from $31 \%^{7}$ to as high as $95 \%{ }^{6,8}$.

54 Studies of the biological/intact lower-limb have found that the ankle can generate a $55241 \%$ energy return ${ }^{7}$. Hence, an ESR foot falls a long way short of replacing the 56 mechanical performance of the biological limb. Closer examination of the dynamics 57 of ESR feet identifies several parameters that are capable of affecting the performance of amputee runners when using these feet. This includes the original shape, the length of the foot, the overall dynamic elastic response to impulse synchronisation and metabolic cost.

By definition the dynamic characteristics of ESR feet are their natural 62 frequency, mode shapes and damping factors ${ }^{9-11}$. Although running with ESR feet is 63 an impulse driven action, the natural frequency of the spring-mass system plays an 64 important role to facilitate the transition from vibration to impulse. Other factors affecting performance of runners using ESR feet could be the excessive metabolic cost, specially due to lack of gait symmetry as observed in unilateral amputees ${ }^{12}$.

67 The effect of each factor needs to be studied individually and their influence on 68 motion can then be better understood.

69 Over the years, debates of fairness of lower-limb prosthesis running 70 technology in sport were raised ${ }^{13-15}$. To address this issue, research to investigate 71 static and dynamic characteristics of various prosthetic feet have been carried out. 72 Lehmann et al. conducted studies to evaluate the biomechanical and metabolic 73 performance differences between two different prosthetic foot designs ${ }^{16}$. This study used SACH (Solid-Ankle Cushion-Heal) prosthetic feet to test for dynamic elastic 
75 response. It was found that the natural frequencies of oscillation for the prosthetic 76 feet were too high to provide energy storage and release that could be synchronised 77 with the kinematic requirements. This finding is not unexpected as the feet used for 78 this test were not designed to store and release a large amount of strain energy such as those made by Össur (Flex-Run) or Blatchford (BladeXT). Noroozi et al. 80 investigated the link between gait symmetry and the effect of dynamic elastic 81 response of the ESR foot to impulse in unilateral and bilateral amputees ${ }^{17}$. Noroozi et al. hypothesised that human input impulse, is needed in order to compensate for loss of energy in one step. This impulse can only assist the motion if it's applied at the right moment and with a force trajectory that closely maps onto the foot. This phenomenon could potentially enhance performance if the foot is used at its optimum dynamic characteristics.

The effect of lack of symmetry due to dissimilar stiffness's on energy transfer rate was investigated by Aslani et al. ${ }^{12}$. It was demonstrated that energy consumption due to lack of gait symmetry is higher than that in symmetric gait and will cause severe fatigue over longer running durations, such as in 200 or 400 metre sprints. It can be shown that an able-bodied individual having a symmetric gait uses

92 less energy than a unilateral amputee when walking ${ }^{18-20}$. Oudenhoven et al. also 93 indicated that the stiffness of the prosthesis is an important parameter to optimize 94 running performance. With this information, the athletes can regulate the leg stiffness 95 during distance running at their preferred step frequencies ${ }^{21}$. These findings infer running efficiency/improved performance can be gained if the running gait can be

97 made symmetrical. Therefore, knowledge of the dynamic characteristics of such feet 98 is important to assist in developing a symmetrical running gait. 
99 This paper presents the modal analysis results of nine stiffness categories of 100 Össur Flex-Run ESR feet in order to understand their dynamic characteristics 101 (natural frequencies, damping and mode shapes). The effect of over-load and under102 loading of the ESR foot on the natural frequencies is also presented.

103 The findings presented in this paper are of importance as the data is not 104 currently available elsewhere. The data is needed to better understand the role 105 dynamic characteristics of the foot plays when prescribing the prosthesis for walking 106 or running.

107

108

Methods

109 The experimental procedure and methodology used to determine the natural 110 frequencies, mode shapes and damping factor of the Össur feet is discussed in this 111 section.

112

\section{3 Össur Flex-Run}

114 The Flex-Run is described as featuring a long toe lever and efficient energy return 115 (https://www.ossur.com/prosthetic-solutions/products/sport-solutions/flex-run). The 116 full length keel/toe lever is designed to match the length of the sound foot to provide 117 improved support to the prosthetic limb during late stance. It is claimed that the users 118 spend equal time on the prosthetic foot and natural limb to provide improved walking 119 dynamics and reduced impact to the sound limb. This could lead to improved walking 120 symmetry and reduced impact to the sound limb. Meanwhile, vertical forces 121 generated at heel contact are stored and translated into a linear motion described as 122 Active Tibia Progression. This action is designed to reduce the need to actively push 
123 the body forward using the contralateral foot and also equalizes stride length. The

124 benefit of this could be a more natural gait and reduced walking effort.

125 The Flex-Run is offered in a range of stiffness values, divided into specified

126 categories and are prescribed according to the mass of the amputee through the

127 stiffness prescription guide from Össur (Table 1). It should be noted, that little or no

128 consideration for the specific ability or desired activity level of the amputee is taken

129 into account in the prescription guide.

130

131 Table 1: Flex Run stiffness prescription guide

\begin{tabular}{lcc}
\hline $\begin{array}{l}\text { High to } \\
\text { Extreme } \\
\text { Impact Level }\end{array}$ & Weight kg & Weight lbs. \\
\hline 1LO & $37-44$ & $81-96$ \\
\hline 2LO & $45-52$ & $97-115$ \\
\hline 3LO & $53-59$ & $116-130$ \\
\hline 4LO & $60-68$ & $131-150$ \\
\hline 5LO & $69-77$ & $151-170$ \\
\hline 6 LO & $78-88$ & $171-194$ \\
\hline 7LO & $89-100$ & $195-220$ \\
\hline 8LO & $101-116$ & $221-256$ \\
\hline 9LO & $117-130$ & $257-287$ \\
\hline
\end{tabular}

132

133 Due to the distinct difference in the stiffness of the feet, they will be

134 distinguished by their rating names assigned by the manufacturer as 1LO-9LO 135 (Figure 1).

Figure 1: Full range of Flex-Run Categories.

137

138

Modal Analysis

139 Modal analysis is a well-established experimental method for identifying modal 140 parameters (frequency, mode shapes and damping) in any static elastic 141 structure/system. The technique used to extract these parameters is called 
142 Experimental Modal Analysis (EMA) [21, 22]. The test structure is artificially excited 143 by using either an impact hammer, or one or more shakers. A force transducer is 144 used to measure the input excitation force to the system while the output response of 145 the system is normally measured by using accelerometers. Input and output 146 vibration signals of several locations of the system are determined to obtain a 147 discrete number of Frequency Response Functions (FRFs). Then, the FRF obtained 148 undergoes curve fitting to extract the modal frequencies, modal damping and residue 149 mode shape of the system [23, 24].

150 Complete modal analysis investigations were conducted on nine Össur ESR 151 feet. A mass of $53 \mathrm{~kg}$ was attached to each of the nine feet and a full modal analysis 152 was conducted for every foot-mass system combination. In each case, the masses 153 were secured in such a way that the line of action of the total weight passed through 154 the ground reaction point of the foot creating a balanced/equilibrium condition 155 (Figure 2). The fixings were approximately 120 degrees apart and each had enough 156 slack to ensure the displacements in all three orthogonal directions were not suppressed.

Figure 2: Experimental set-up of free-free modal testing. method throughout the study to determine the elastic and damping properties of the 164 feet ${ }^{22}$. An impact hammer, tri-axial accelerometer, in-house data acquisition system and modal analysis software were used to investigate the dynamic characteristics. 
signal was the excitation force from the manual impact hammer whereas the output signal was the response due to impact measured by the accelerometer. A data acquisition (DAQ) system consisting of National Instrument NI-USB-9234 modules controlled by the DASYLab software was used. A manual impact hammer was connected to channel 1 of the National Instrument (NI) dynamic analyzer and a triaxial accelerometer was connected to channel 2, 3 and 4 respectively. In this experiment, a roving tri-axial accelerometer was used while manual impact hammer was excited at fixed degrees of freedom, i.e., point 13 and 2 in the $x$-axis and z-axis respectively. The tri-axial accelerometer was roved from point 1 to point 18 measuring the response of the structure in the $x, y$ and $z$ directions and this gave a single-input, single-output (SISO) analysis. A sampling rate of 2048 samples/sec was used, and the vibration signal was collected for 2 seconds, so a total of 4096 samples were recorded for post-processing. The modal analysis software (ME'Scope software) was used to draw the three-dimensional structural model of the test rig in coordinate points where every point was connected by straight lines as shown in Figure 3. The displayed point numbers represented each discrete location as in the actual ESR foot.

Furthermore, the FRF estimations acquired through DASYLab software were post-processed by using Me'Scope software. A polynomial curve fitting method was used in the software to extract the modal parameters. Thus, the mode shape obtained corresponding to each vibration mode was recorded and animated using the wire mesh model drawn. Modal damping, $2 \sigma$ is approximately equal to the width of the resonance peak at $70.7 \%$ of the FRF peak magnitude value, which is the same as half of the peak magnitude value squared. Hence, $2 \sigma$ is the width at the half power point of a resonance peak in the unit of $\mathrm{rad} / \mathrm{s}$ or $\mathrm{Hz}$. 
Figure 3: Wire-mesh model of Flex-Run used for modal analysis

194

195

Table 2: Detailed instrumentation characteristics

\begin{tabular}{|c|c|}
\hline INSTRUMENTS & DESCRIPTION \\
\hline $\begin{array}{l}\text { 1LO-9LO Flex-Run } \\
\text { feet }\end{array}$ & Used as test rig to perform modal analysis \\
\hline $\begin{array}{l}\text { PCB Impact Hammer, } \\
\text { Model } 086 C 03\end{array}$ & $\begin{array}{l}\text { Sensitivity: } 2.25 \mathrm{mv} / \mathrm{N} \\
\text { Tip type: medium tip with vinyl cover } \\
\text { Hammer mass: } 0.16 \mathrm{~kg} \\
\text { Frequency range: } 8 \mathrm{kHz} \\
\text { Amplitude range: } \pm 2200 \mathrm{~N} \text { peak }\end{array}$ \\
\hline $\begin{array}{l}\text { PCB ICP } \\
\text { Accelerometer, Model } \\
\text { 356B18 }\end{array}$ & $\begin{array}{l}\text { Sensitivity: } 1000 \mathrm{mv} / \mathrm{g} \\
\text { Frequency range: }( \pm 5 \%) 0.5 \text { to } 3000 \mathrm{~Hz} \\
\text { Amplitude range: } \pm 5 \mathrm{~g} \text { peak }\end{array}$ \\
\hline $\begin{array}{l}\text { NI USB Dynamics } \\
\text { Signal Acquisition } \\
\text { Module, Model NI- } \\
\text { USB } 9234\end{array}$ & $\begin{array}{l}\text { Number of channels: } 4 \\
\text { ADC resolution: } 24 \text { bits } \\
\text { Type of ADC: Delta sigma (with analog pre- } \\
\text { filtering) }\end{array}$ \\
\hline DASYLab v10 & $\begin{array}{l}\text { Sampling rate: } 2048 \text { samples/sec } \\
\text { Block Size: } 4096 \\
\text { Channel 1: Impact hammer } \\
\text { Channel 2: Accelerometer x-axis } \\
\text { Channel 3: Accelerometer y-axis } \\
\text { Channel 4: Accelerometer z-axis } \\
\text { Averaging: } 5 \text { for static conditions } \\
\text { Windowing: } \\
\text { Force for excitation signal } \\
\text { Exponential for response signal }\end{array}$ \\
\hline ME'Scope v6.0 & $\begin{array}{l}\text { To process collected data from NI-DASYLab } \\
\text { To define the structural geometry for } \\
\text { frequency response function (FRF) modal } \\
\text { Analysis } \\
\text { To determine the natural frequencies, } \\
\text { damping and animated mode shapes after } \\
\text { curve fitting process }\end{array}$ \\
\hline
\end{tabular}

196

197

198

199

200

Using the damped natural frequency and damping obtained from modal analysis, the undamped natural frequency can be calculated from the damped natural frequency (equation 1). 
$201 \omega_{d}=\omega_{o} \sqrt{\left(1-\zeta^{2}\right)}$

202

203

where, $\omega_{d}=$ damped natural frequency $(\mathrm{rad} / \mathrm{s}), \omega_{o}=$ undamped natural frequency

$204(\mathrm{rad} / \mathrm{s})$ and $\zeta=$ damping ratio.

205

206 By using the constant mass of $53 \mathrm{~kg}$ and the undamped natural frequency, the 207 stiffness of each foot can be determined (equation 2).

208

209

$$
\omega_{o}=\sqrt{\frac{k}{m}}
$$

210

211 where, $k=$ stiffness $(\mathrm{N} / \mathrm{m}), \mathrm{m}=\operatorname{mass}(\mathrm{Kg})$

212

213

\section{Results}

214 Table 3 presents the natural frequencies and damping of 1LO-9LO feet with fixed $21553 \mathrm{~kg}$ mass system. The results show that the system possesses the same natural 216 frequency when excited by knocks in $X$ and $Z$ direction. This implies all excitations in 217 these two directions will always excite this natural. This is close to the natural 218 frequency of the running gait for most athletes which has been shown in previous 219 research to reach $4.31 \mathrm{~Hz}$ during sprinting [25].

220

221 Table 3: Dynamic characteristics of 1LO-9LO feet with fixed 53kg mass

\begin{tabular}{lllll}
\hline Flex-run & $\begin{array}{l}1^{\text {st }} \text { Natural } \\
\text { Frequency } \\
\text { knocked in X-dir } \\
(\mathrm{Hz})\end{array}$ & $\begin{array}{l}\text { Damping } \\
(\%)\end{array}$ & $\begin{array}{l}1^{\text {st }} \text { Natural } \\
\text { Frequency } \\
\text { knocked in Z-dir } \\
(\mathrm{Hz})\end{array}$ & Damping (\%) \\
\hline $1 \mathrm{LO}$ & 3.94 & 1.55 & 3.90 & 1.93 \\
\hline
\end{tabular}




\begin{tabular}{lllll}
\hline 2LO & 4.02 & 1.66 & 4.04 & 2.06 \\
\hline $3 \mathrm{LO}$ & 4.13 & 1.65 & 4.14 & 1.54 \\
\hline $4 \mathrm{LO}$ & 4.24 & 1.61 & 4.24 & 1.73 \\
\hline $5 \mathrm{LO}$ & 4.64 & 1.43 & 4.64 & 1.63 \\
\hline $6 \mathrm{LO}$ & 4.87 & 1.65 & 4.78 & 1.88 \\
\hline $7 \mathrm{LO}$ & 5.04 & 1.77 & 5.00 & 1.84 \\
\hline $8 \mathrm{LO}$ & 5.21 & 1.8 & 5.22 & 1.81 \\
\hline $9 \mathrm{LO}$ & 5.29 & 1.54 & 5.33 & 1.69 \\
\hline
\end{tabular}

Table 4 presents the undamped natural frequency and the stiffness of each

foot using equations 1 and 2 . The results show that both the undamped natural

to the highest stiffness category (9LO).

227

228 Table 4: Dynamic characteristics of 1LO-9LO based on fixed 53kg mass

\begin{tabular}{lcccc}
\hline Flex-run & $\begin{array}{l}\text { Damped natural } \\
\text { frequency }(\mathrm{Hz})\end{array}$ & $\begin{array}{l}\text { Damping } \\
(\%)\end{array}$ & $\begin{array}{l}\text { Undamped } \\
\text { natural } \\
\text { frequency }(\mathrm{Hz})\end{array}$ & $\begin{array}{l}\text { Stiffness } \\
(\mathrm{N} / \mathrm{m})\end{array}$ \\
\hline $1 \mathrm{LO}$ & 3.920 & 1.740 & 3.921 & 32161.72 \\
\hline 2LO & 4.030 & 1.860 & 4.031 & 33993.51 \\
\hline $3 \mathrm{LO}$ & 4.135 & 1.595 & 4.136 & 35784.68 \\
\hline $4 \mathrm{LO}$ & 4.240 & 1.670 & 4.241 & 37626.04 \\
\hline $5 \mathrm{LO}$ & 4.640 & 1.530 & 4.641 & 45058.14 \\
\hline $6 \mathrm{LO}$ & 4.825 & 1.765 & 4.826 & 48726.54 \\
\hline $7 \mathrm{LO}$ & 5.020 & 1.805 & 5.021 & 52745.4 \\
\hline $8 \mathrm{LO}$ & 5.215 & 1.805 & 5.216 & 56922.73 \\
\hline $9 \mathrm{LO}$ & 5.310 & 1.615 & 5.311 & 59011.67 \\
\hline
\end{tabular}

229

Figure 4 shows that with the stiffness of 1LO-9LO known, and assuming the boundary condition is fixed, natural frequency can be predicted based on different mass or masses to be used on a specific foot due to the linearity of the data. 
237 The results show that by simple adjustment of the stiffness when used with 238 the same body mass, the natural frequency can be controlled. Noroozi et al. 239 described the behaviour of the mass and foot system to be similar to a trampoline ${ }^{9}$, $240{ }^{11}$. If the frequency of the bouncing action during running matches the natural 241 frequency of the perceived mass/spring system then the mass will vibrate. This 242 cyclic rhythm is a form of energy input into the system that is needed to maintain this 243 steady state cyclic/periodic motion, by replacing the loss of energy in one cycle due 244 to damping.

245 Damping is an important factor in this study. Damping data is not readily 246 available for ESR feet. The decay rate has been used to predict the drop in 247 amplitude of the vibration per unit time. Using the decay rate makes it possible to 248 calculate the percentage drop in amplitude with respect to time elapsed. The 249 damping characteristic for a given system must be physically measured as it cannot 250 be determined using simulation tools. The damping characteristic of the feet have 251 been experimentally determined and the damping of the first bending mode was 252 found to range between $1.5-2.0 \%$. This low damping reduces the energy dissipation 253 in one cycle and thus less energy input into the system is required to maintain the 254 steady state cyclic motion before take-off from the ground.

255 These modal test results also show the mode shape that is most relevant or 256 suitable for the running action (Figure 5). The mode shapes of all Flex-Run feet are 257 supplied separately as Supplemental Digital Content. It was noticed during this 258 investigation that the Flex-Run tested possessed a unique geometrical characteristic 259 that initiates or promotes a natural and perpetual forward leaping response when 260 excited as its natural frequency. The recoil motion during bounce gave the system a 261 perpetual forwards motion even without any forward excitation force. This important 
262 phenomenon, known as Active Tibia Progression by Össur, could reduce the need to 263 actively push the body forward to have a more natural gait and also reduces the 264 walking effort. Without further testing it can only be hypothesised that this could be 265 due to the special geometrical features of these Össur feet, where energy could be 266 stored in the foot in one direction and released naturally in a different direction that is 267 usually aligned with the direction of the run. In a bilateral amputee this can have 268 another significant effect, which is steady-state symmetric beat frequency that can 269 enhance performance over longer distance runs. Further study of this phenomenon 270 will be the subject of future publications.

271

Figure 5: First bending mode of $1 \mathrm{LO}$ at $3.94 \mathrm{~Hz}$ and $3.90 \mathrm{~Hz}$ with free-free boundary

\section{Discussion}

Although modal analysis is a powerful tool it is highly sensitive to the influence of other parameters such as changes in boundary conditions that can affect the dynamic response to excitation. This is a very important issue as in a free-free modal testing, the change of boundary condition during modal testing changes due to foot flexure and alignment which will result in discrepancies in the dynamic characteristics obtained. This also implies that using these feet with anything other than strings to hold them in position, such as dedicated test rigs will result in modal data that are not representation of the foot and mass system in isolation. That is because dissimilar material rigs with much higher stiffness will substantially change 285 the boundary condition and the results will show the natural frequencies of the test 286 rig instead of the foot and mass system. 
287 This paper indirectly demonstrates the dynamic flexibility of CFRP composite 288 materials for application in advanced dynamic systems. Specific detail regarding the 289 individual constituents of the material and its construction are unknown. However, 290 the composite laminates used to manufacture running specific feet are all 291 unidirectional and woven carbon pre-impregnated epoxy. The laminate lay ups are 292 non-symmetric and uses a specific laminate lay up for each foot category. Laminates 293 are autoclaved cured and then machined to size.

\section{Conclusion}

296 Nine Össur Flex-Run feet, constituting the full range of feet that are commercially 297 available (i.e. 1LO-9LO), were investigated and the dynamic characteristic results 298 are presented. Currently no such data is available regarding these feet and the 299 influence of mass, stiffness and natural frequency is not properly understood.

300 This paper presents the damping, mode shapes and natural frequencies of all 301 of these feet. This information will be needed in order to better predict how the 302 dynamic data can influence the gait pattern and symmetric transition from walking to 303 running. From the first bending mode shape, it was noticed during this investigation 304 that the Flex-Run possessed a unique geometrical characteristic that initiates or 305 promotes a natural and perpetual forward leaping response without any forward 306 excitation force when excited as its natural frequency. Further study of this 307 phenomenon is warranted.

309 Acknowledgements

310 The authors wish to thank the Royal Academy of Engineering who sponsored this 311 joint collaboration link between the universities. The authors also wish to 
acknowledge the financial support and advice given by Newton-Ungku Omar Fund:

Mobility Grant (IF006-2016), Advanced Shock and Vibration Research (ASVR)

Group and other project collaborators.

\section{Author contribution}

All authors contributed equally in the preparation of this manuscript

\section{Declaration of conflicting interests}

The authors declare that there is no conflict of interest.

\section{References}

1. Bragaru M, Dekker R and Geertzen JH. Sport prostheses and prosthetic adaptations for the upper and lower limb amputees: an overview of peer reviewed literature. Prosthetics and Orthotics International. 2012; 36: 290-6.

2. De Luigi AJ and Cooper RA. Adaptive Sports Technology and Biomechanics: Prosthetics. PM\&R. 2014; 6: S40-S57.

3. Goffette J. Prosthetic dreams: "Wow Effect", mechanical paradigm and modular body prospects on prosthetics. Sport in Society. 2017: 1-8.

4. Harrison RN, Lees A, McCullagh PJJ and Rowe WB. A bioengineering analysis of human muscle and joint forces in the lower limbs during running. Journal of Sports Sciences. 1986; 4: 20118.

5. Hafner BJ, Sanders JE, Czerniecki JM and Fergason J. Transtibial energy-storage-and-return prosthetic devices: A review of energy concepts and a proposed nomenclature. J Rehabil Res Dev. 2002; 39: 1-11.

6. Nolan L. Carbon fibre prostheses and running in amputees: a review. Foot and ankle surgery : official journal of the European Society of Foot and Ankle Surgeons. 2008; 14: 125-9.

7. Czerniecki JM, Gitter A and Munro C. Joint Moment and Muscle Power Output Characteristics of Below Knee Amputees during Running - the Influence of Energy Storing Prosthetic Feet. J Biomech. 1991; 24: 63-75.

8. Brüggemann G-P, Arampatzis A, Emrich F and Potthast W. Biomechanics of double transtibial amputee sprinting using dedicated sprinting prostheses. Sports Technology. 2008; 1: 220-7.

9. Noroozi S, Sewell P, Rahman AGA, Vinney J, Chao OZ and Dyer B. Modal analysis of composite prosthetic energy-storing-and-returning feet: an initial investigation. P I Mech Eng P-J Spo. 2013; 227: 39-48.

10. Vinney J, Noroozi S, Rahman AGA, et al. Analysis of Composite Prosthetic Energy-Storingand-Returning (ESR) feet: A comparison between FEA and the experimental analysis. International Journal of COMADEM. 2012; 15: 19-28.

11. Noroozi S, Sewell P, Rahman AGA, Vinney J, Chao OZ and Dyer B. Performance enhancement of bi-lateral lower-limb amputees in the latter phases of running events: an initial investigation. $P$ I Mech Eng P-J Spo. 2013; 227: 105-15. 
352 12. Aslani N, Noroozi S, Yee KS, Chao AOZ and Maggs C. Simulation of gait asymmetry and 353 energy transfer efficiency between unilateral and bilateral amputees. Sports Engineering. 2016; 19: 354 163-70.

355 13. Jones $C$ and Wilson C. Defining advantage and athletic performance: The case of Oscar 356 Pistorius. European Journal of Sport Science. 2009; 9: 125-31.

357 14. Dyer BTJ, Noroozi S, Redwood S and Sewell P. The design of lower-limb sports prostheses: 358 fair inclusion in disability sport. Disability \& Society. 2010; 25: 593-602.

359 15. Burkett $B$, McNamee $M$ and Potthast $W$. Shifting boundaries in sports technology and 360 disability: equal rights or unfair advantage in the case of Oscar Pistorius? Disability \& Society. 2011; 361 26: 643-54.

362 16. Lehmann JF, Price R, Boswellbessette S, Dralle A, Questad K and Delateur BJ. Comprehensive 363 Analysis of Energy-Storing Prosthetic Feet - Flex Foot and Seattle Foot Versus Standard Sach Foot. 364 Arch Phys Med Rehab. 1993; 74: 1225-31.

365 17. Noroozi S, Rahman AGA, Khoo SY, et al. The dynamic elastic response to impulse 366 synchronisation of composite prosthetic energy storing and returning feet. $P$ I Mech Eng P-J Spo. 367 2014; 228: 24-32.

368 18. Kuo AD and Donelan JM. Dynamic Principles of Gait and Their Clinical Implications. Physical 369 Therapy. 2010; 90: 157-74.

370 19. Ellis RG, Howard KC and Kram R. The metabolic and mechanical costs of step time 371 asymmetry in walking. Proceedings of the Royal Society B: Biological Sciences. 2013; 280.

372 20. Archer KR, Castillo RC, MacKenzie EJ and Bosse MJ. Gait Symmetry and Walking Speed 373 Analysis Following Lower-Extremity Trauma. Physical Therapy. 2006; 86: 1630-40.

374 21. Oudenhoven LM, Boes JM, Hak L, Faber GS and Houdijk H. Regulation of step frequency in 375 transtibial amputee endurance athletes using a running-specific prosthesis. J Biomech. 2017; 51: 423768 .

377 22. Brandt A. Noise and vibration analysis: signal analysis and experimental procedures. 378 Chichester: Wiley, 2011, p.xxvi, 438 p.

379 


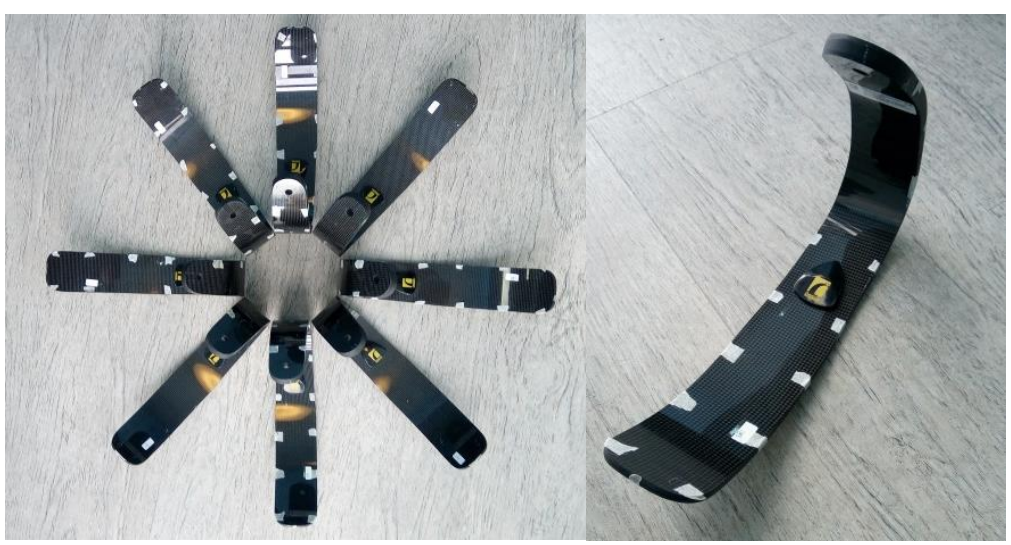

Figure 1: Full range of Flex-Run ${ }^{\mathrm{TM}}$

1
2
3
4
5
6
7
8
9
10
11
12
13
14
15
16
17
18
19
20
21
22
23
24
25
26
27
28
29
30
31
32
33
34
35
36
37
38
39
40
41
42
43
44
45
46
47
48
49
50
51
52
53
54
55
56
57
58
50




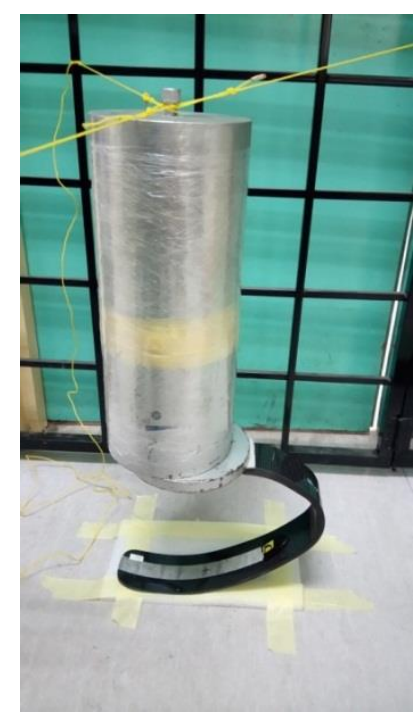

Figure 2: Experimental set-up of free-free modal testing 
Page 19 of 34

Prosthetics \& Orthotics International

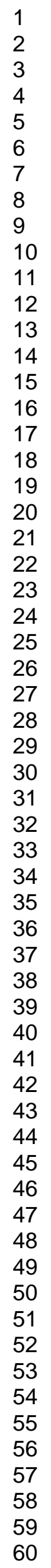

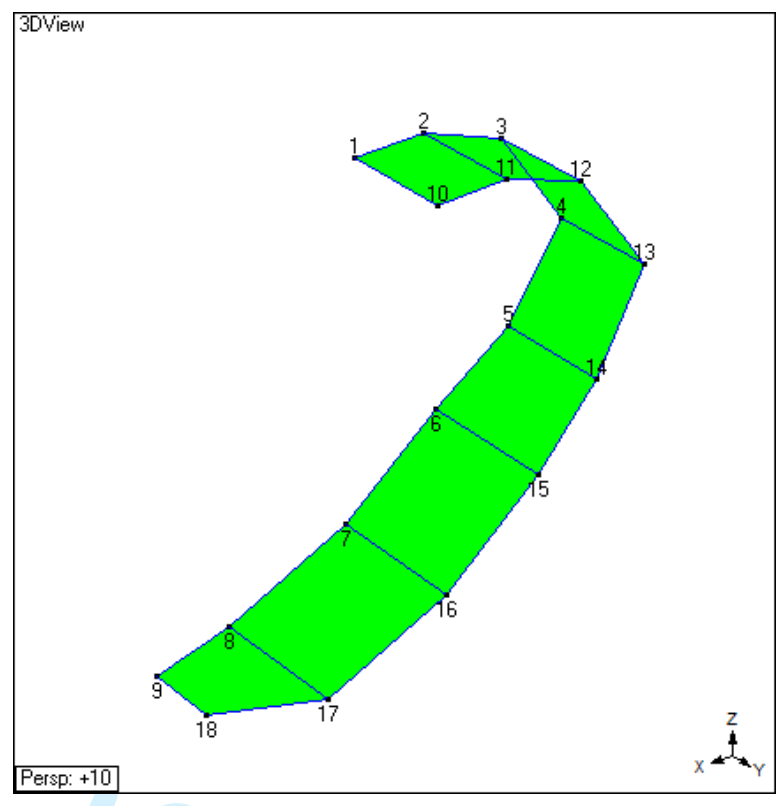

Figure 3: Wire-mesh model of Flex-Run ${ }^{\top \mathrm{M}}$ used for modal analysis

URL: http:/mc.manuscriptcentral.com/tpoi Email: tim.bach@ispoint.org 

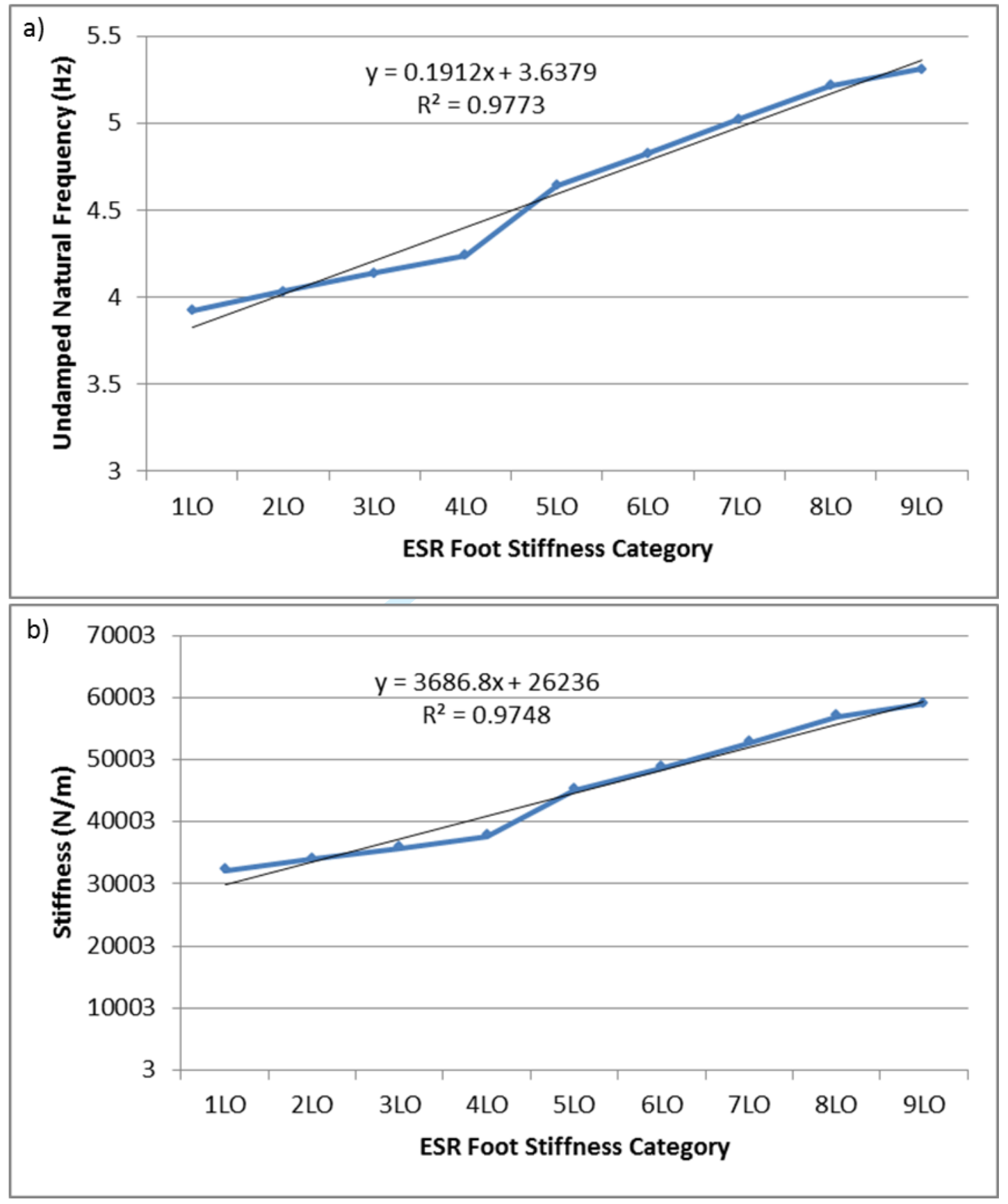

Figure 4: Plot of a) undamped natural frequency $(\mathrm{Hz})$ and b) Stiffness $(\mathrm{N} / \mathrm{m})$ against ESR foot stiffness category.

URL: http:/mc.manuscriptcentral.com/tpoi Email: tim.bach@ispoint.org 
1

2

3

4

5

6

7

8

9

10

11

12

13

14

15

16

17

18

19

20

21

22

23

24

25

26

27

28

29

30

31

32

33

34

35

36

37

38

39

40

41

42

43

44

45

46

47

48

49

50

51

52

53

54

55

56

57

58

59

60

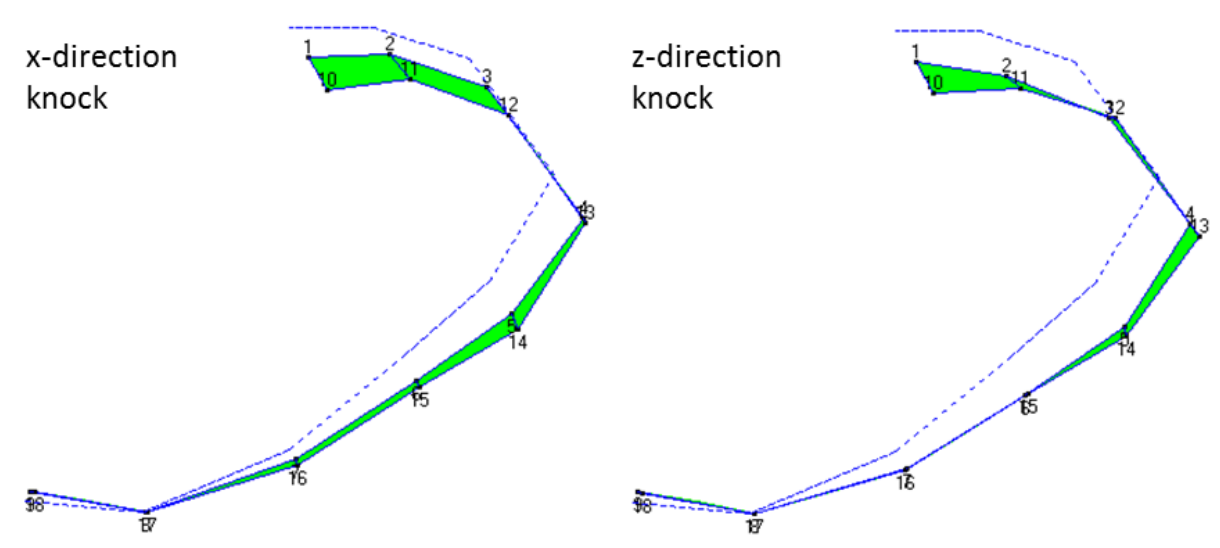

Figure 5: First bending mode of $1 \mathrm{LO}$ at $3.94 \mathrm{~Hz}$ and $3.90 \mathrm{~Hz}$ with free-free boundary condition knocked in X\&Z-direction respectively 
Table 1: Flex-Run ${ }^{\mathrm{TM}}$ Category Selection Chart

\begin{tabular}{lcc}
\hline $\begin{array}{l}\text { High to } \\
\text { Extreme } \\
\text { Impact Level }\end{array}$ & Weight kg & Weight lbs. \\
\hline 1LO & $37-44$ & $81-96$ \\
\hline 2LO & $45-52$ & $97-115$ \\
\hline 3LO & $53-59$ & $116-130$ \\
\hline 4LO & $60-68$ & $131-150$ \\
\hline 5LO & $69-77$ & $151-170$ \\
\hline 6LO & $78-88$ & $171-194$ \\
\hline 7LO & $89-100$ & $195-220$ \\
\hline 8LO & $101-116$ & $221-256$ \\
\hline 9LO & $117-130$ & $257-287$ \\
\hline
\end{tabular}


Table 2: Detailed instrumentation characteristics

\begin{tabular}{|c|c|}
\hline INSTRUMENTS & DESCRIPTION \\
\hline $\begin{array}{l}\text { 1LO-9LO Flex-Run } \\
\text { feet }\end{array}$ & Used as test rig to perform modal analysis \\
\hline $\begin{array}{l}\text { PCB Impact Hammer, } \\
\text { Model 086C03 }\end{array}$ & $\begin{array}{l}\text { Sensitivity: } 2.25 \mathrm{mv} / \mathrm{N} \\
\text { Tip type: medium tip with vinyl cover } \\
\text { Hammer mass: } 0.16 \mathrm{~kg} \\
\text { Frequency range: } 8 \mathrm{kHz} \\
\text { Amplitude range: } \pm 2200 \mathrm{~N} \text { peak }\end{array}$ \\
\hline $\begin{array}{l}\text { PCB ICP } \\
\text { Accelerometer, Model } \\
\text { 356B18 }\end{array}$ & $\begin{array}{l}\text { Sensitivity: } 1000 \mathrm{mv} / \mathrm{g} \\
\text { Frequency range: }( \pm 5 \%) 0.5 \text { to } 3000 \mathrm{~Hz} \\
\text { Amplitude range: } \pm 5 \mathrm{~g} \text { peak }\end{array}$ \\
\hline $\begin{array}{l}\text { NI USB Dynamics } \\
\text { Signal Acquisition } \\
\text { Module, Model NI- } \\
\text { USB } 9234\end{array}$ & $\begin{array}{l}\text { Number of channels: } 4 \\
\text { ADC resolution: } 24 \text { bits } \\
\text { Type of ADC: Delta sigma (with analog pre- } \\
\text { filtering) }\end{array}$ \\
\hline DASYLab v10 & $\begin{array}{l}\text { Sampling rate: } 2048 \text { samples/sec } \\
\text { Block Size: } 4096 \\
\text { Channel 1: Impact hammer } \\
\text { Channel 2: Accelerometer x-axis } \\
\text { Channel 3: Accelerometer y-axis } \\
\text { Channel 4: Accelerometer z-axis } \\
\text { Averaging: } 5 \text { for static conditions } \\
\text { Windowing: } \\
\text { Force for excitation signal } \\
\text { Exponential for response signal }\end{array}$ \\
\hline ME'Scope v6.0 & $\begin{array}{l}\text { To process collected data from NI-DASYLab } \\
\text { To define the structural geometry for } \\
\text { frequency response function (FRF) modal } \\
\text { Analysis } \\
\text { To determine the natural frequencies, } \\
\text { damping and animated mode shapes after } \\
\text { curve fitting process }\end{array}$ \\
\hline
\end{tabular}


Table 3: Dynamic characteristics of 1LO-9LO feet with fixed 53kg mass

\begin{tabular}{lllll}
\hline & $\begin{array}{l}1^{\text {st }} \begin{array}{l}\text { Natural } \\
\text { Frequency } \\
\text { knocked in X-dir. }\end{array} \\
\text { 1LO }\end{array}$ & Damping (\%) & $\begin{array}{l}1^{\text {st }} \text { Natural } \\
\text { Frequency } \\
\text { knocked in Z-dir. }\end{array}$ & Damping (\%) \\
\hline 2LO & 3.94 & 1.55 & 3.90 & 1.93 \\
\hline $3 \mathrm{LO}$ & 4.02 & 1.66 & 4.04 & 2.06 \\
\hline $4 \mathrm{LO}$ & 4.13 & 1.65 & 4.14 & 1.54 \\
\hline $5 \mathrm{LO}$ & 4.24 & 1.61 & 4.24 & 1.73 \\
\hline $6 \mathrm{LO}$ & 4.64 & 1.43 & 4.64 & 1.63 \\
\hline $7 \mathrm{LO}$ & 4.87 & 1.65 & 4.78 & 1.88 \\
\hline $8 \mathrm{LO}$ & 5.04 & 1.77 & 5.00 & 1.84 \\
\hline $9 \mathrm{LO}$ & 5.21 & 1.8 & 5.22 & 1.81 \\
\hline
\end{tabular}


Table 4: Dynamic characteristics of $1 \mathrm{LO}-9 \mathrm{LO}$ based on fixed $53 \mathrm{~kg}$ mass

\begin{tabular}{lcrrc}
\hline Flex-run & $\begin{array}{l}\text { Damped natural } \\
\text { frequency }\end{array}$ & $\begin{array}{l}\text { Damping } \\
(\%)\end{array}$ & $\begin{array}{l}\text { Undamped } \\
\text { natural } \\
\text { frequency }\end{array}$ & Stiffness \\
\hline 1LO & 3.920 & 1.740 & 3.921 & 32161.72 \\
\hline 2LO & 4.030 & 1.860 & 4.031 & 33993.51 \\
\hline $3 \mathrm{LO}$ & 4.135 & 1.595 & 4.136 & 35784.68 \\
\hline $4 \mathrm{LO}$ & 4.240 & 1.670 & 4.241 & 37626.04 \\
\hline $5 \mathrm{LO}$ & 4.640 & 1.530 & 4.641 & 45058.14 \\
\hline $6 \mathrm{LO}$ & 4.825 & 1.765 & 4.826 & 48726.54 \\
\hline 7LO & 5.020 & 1.805 & 5.021 & 52745.4 \\
\hline $8 \mathrm{LO}$ & 5.215 & 1.805 & 5.216 & 56922.73 \\
\hline 9LO & 5.310 & 1.615 & 5.311 & 59011.67 \\
\hline
\end{tabular}


Figure S1: First bending mode of $1 \mathrm{LO}$ at $3.94 \mathrm{~Hz}$ and $3.90 \mathrm{~Hz}$ with free-free boundary condition knocked in X\&Z-direction respectively 
1

2

3

4

5

6

7

8

9

10

11

12

13

14

15

16

17

18

19

20

21

22

23

24

25

26

27

28

29

30

31

32

33

34

35

36

37

38

39

40

41

42

43

44

45

46

47

48

49

50

51

52

53

54

55

56

57

58

59

60

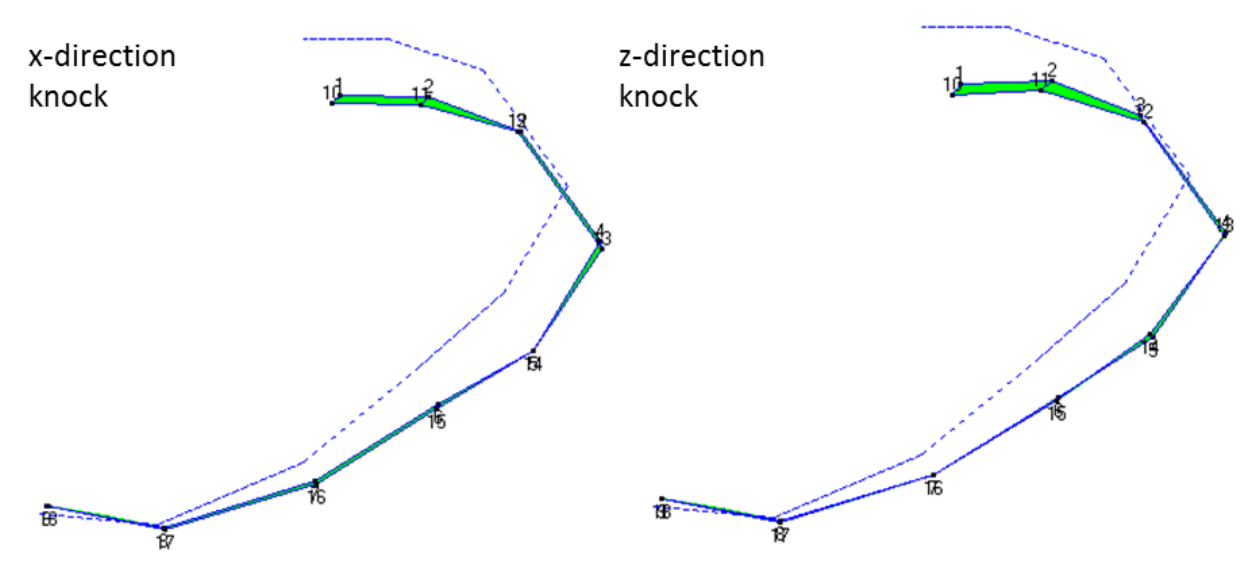

Figure S2: First bending mode of $2 \mathrm{LO}$ at $4.02 \mathrm{~Hz}$ and $4.04 \mathrm{~Hz}$ with free-free boundary condition knocked in $\mathrm{X}$ and Z-direction respectively 
Figure S3: First bending mode of $3 \mathrm{LO}$ at $4.13 \mathrm{~Hz}$ and $4.14 \mathrm{~Hz}$ with free-free boundary condition knocked in $\mathrm{X}$ and Z-direction respectively 
1

2

3

4

5

6

7

8

9

10

11

12

13

14

15

16

17

18

19

20

21

22

23

24

25

26

27

28

29

30

31

32

33

34

35

36

37

38

39

40

41

42

43

44

45

46

47

48

49

50

51

52

53

54

55

56

57

58

59

60

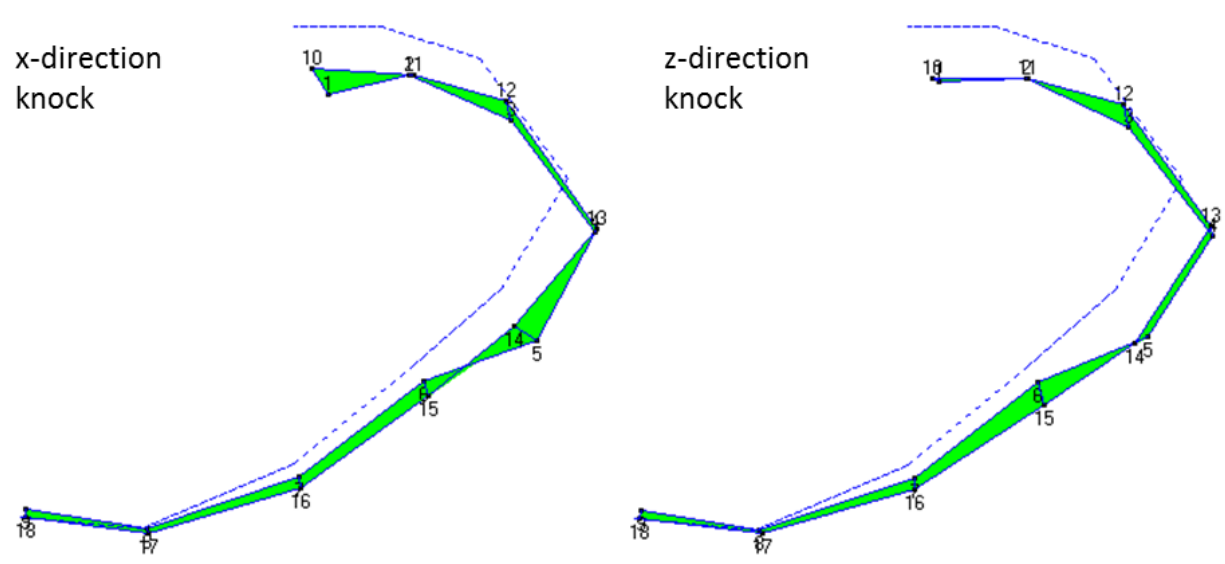

Figure S4: First bending mode of $4 \mathrm{LO}$ at $4.24 \mathrm{~Hz}$ with free-free boundary condition knocked in $\mathrm{X}$ and $\mathrm{Z}$-direction respectively 


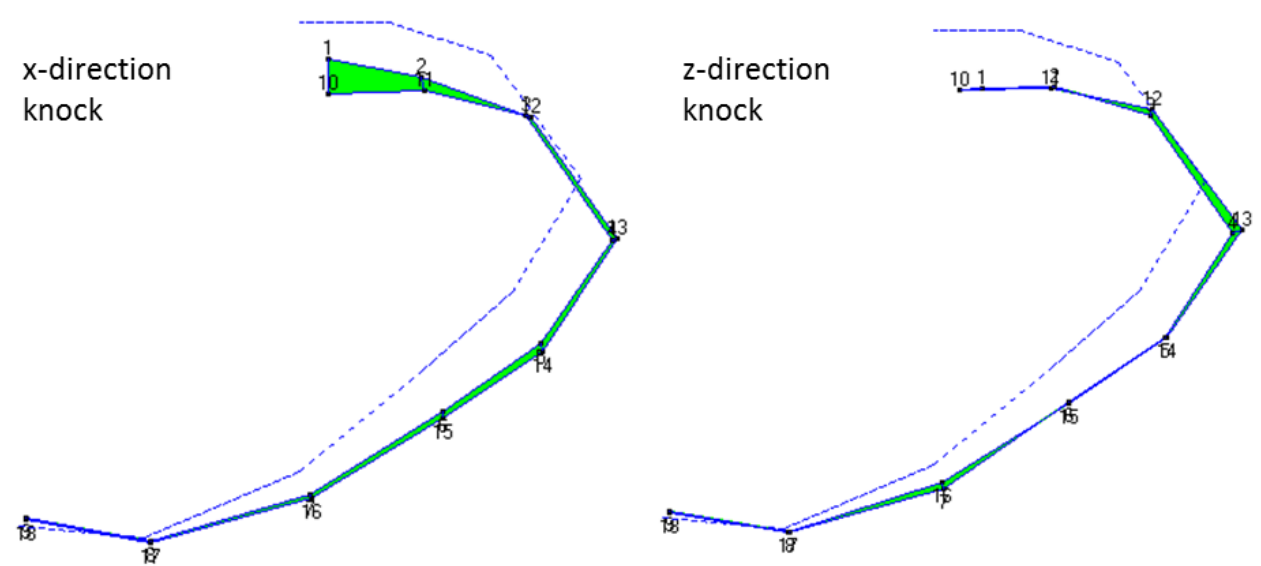

Figure S5: First bending mode of $5 \mathrm{LO}$ at $4.64 \mathrm{~Hz}$ with free-free boundary condition knocked in $x$ and Z-direction respectively 
1

2

3

4

5

6

7

8

9

10

11

12

13

14

15

16

17

18

19

20

21

22

23

24

25

26

27

28

29

30

31

32

33

34

35

36

37

38

39

40

41

42

43

44

45

46

47

48

49

50

51

52

53

54

55

56

57

58

59

60

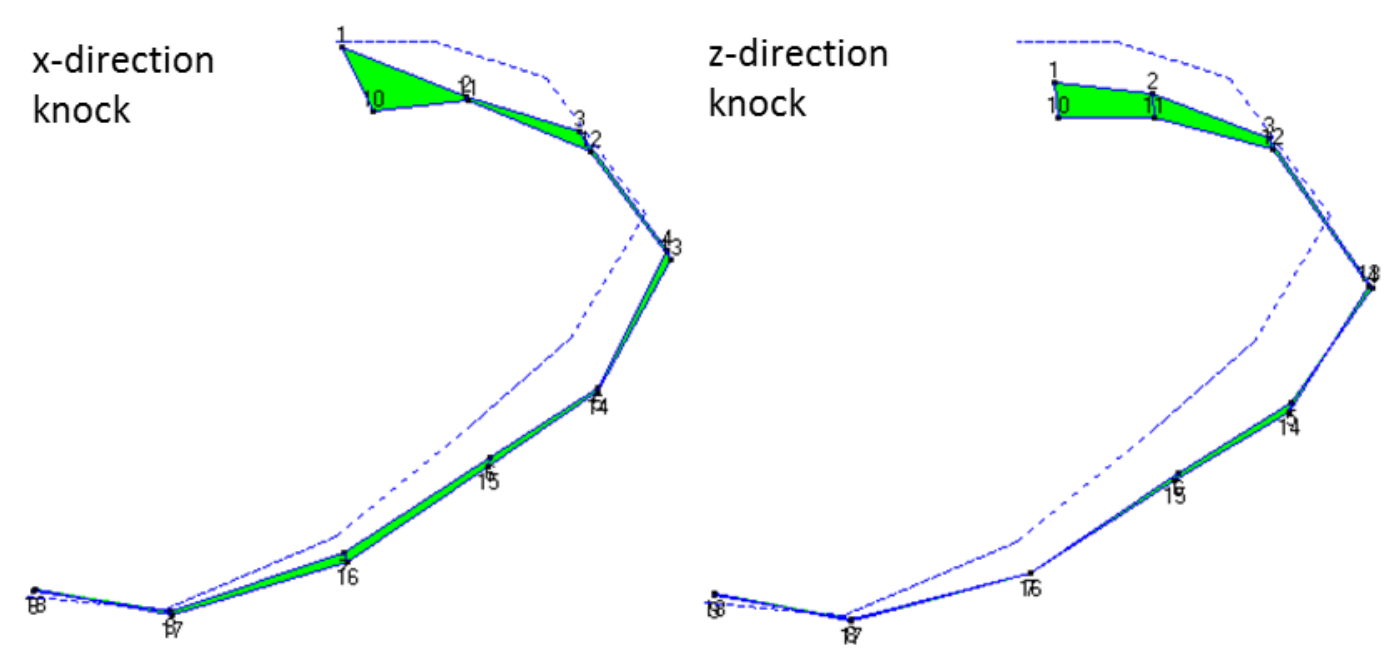

Figure S6: First bending mode of $6 \mathrm{LO}$ at $4.87 \mathrm{~Hz}$ and $4.78 \mathrm{~Hz}$ with free-free boundary condition knocked in $\mathrm{X}$ and Z-direction respectively 
Prosthetics \& Orthotics International

Page 32 of 34

$$
\begin{aligned}
& 1 \\
& 2 \\
& 3 \\
& 4 \\
& 5 \\
& 6 \\
& 7 \\
& 8 \\
& 9 \\
& 10 \\
& 11 \\
& 12 \\
& 13 \\
& 14 \\
& 15 \\
& 16 \\
& 17 \\
& 18 \\
& 19 \\
& 20 \\
& 21 \\
& 22 \\
& 23 \\
& 24 \\
& 25 \\
& 26 \\
& 27 \\
& 28 \\
& 29 \\
& 30 \\
& 31 \\
& 32 \\
& 33 \\
& 34 \\
& 35 \\
& 36 \\
& 37 \\
& 50 \\
& 38 \\
& 39 \\
& 50 \\
& 50 \\
& 53 \\
& 4 \\
& 4 \\
& 4 \\
& 50 \\
& 43 \\
& 44 \\
& 45 \\
& 46 \\
& 47 \\
& 48 \\
& \hline
\end{aligned}
$$

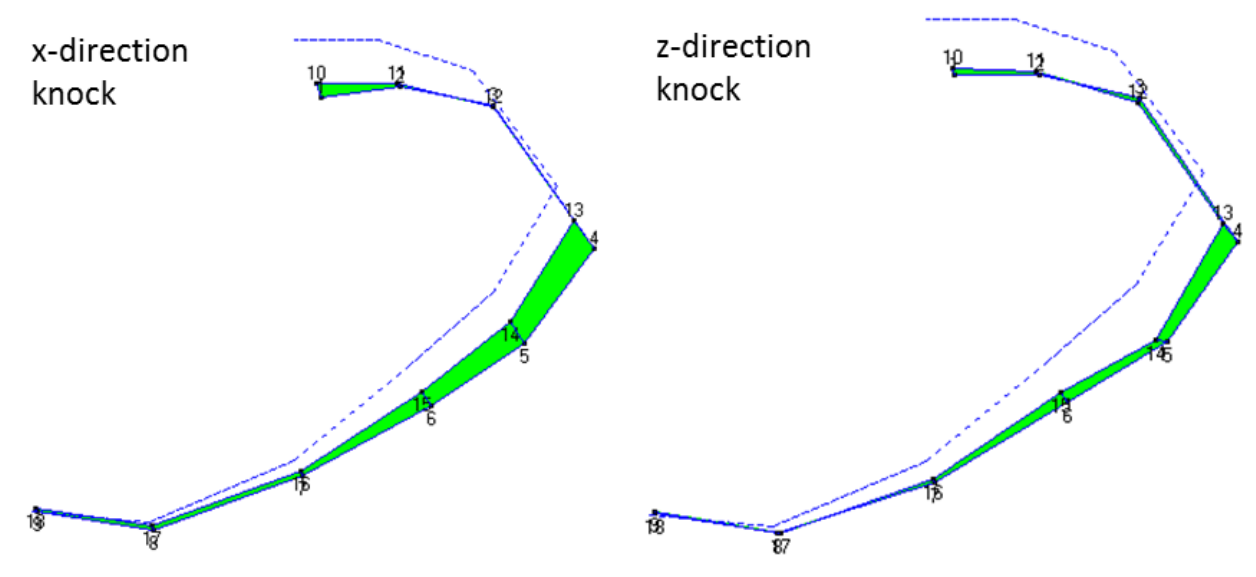

Figure S7: First bending mode of $7 \mathrm{LO}$ at $5.04 \mathrm{~Hz}$ and $5.00 \mathrm{~Hz}$ with free-free boundary condition knocked in $\mathrm{X}$ and $\mathrm{Z}$-direction respectively

URL: http:/mc.manuscriptcentral.com/tpoi Email: tim.bach@ispoint.org 
1

2

3

4

5

6

7

8

9

10

11

12

13

14

15

16

17

18

19

20

21

22

23

24

25

26

27

28

29

30

31

32

33

34

35

36

37

38

39

40

41

42

43

44

45

46

47

48

49

50

51

52

53

54

55

56

57

58

59

60

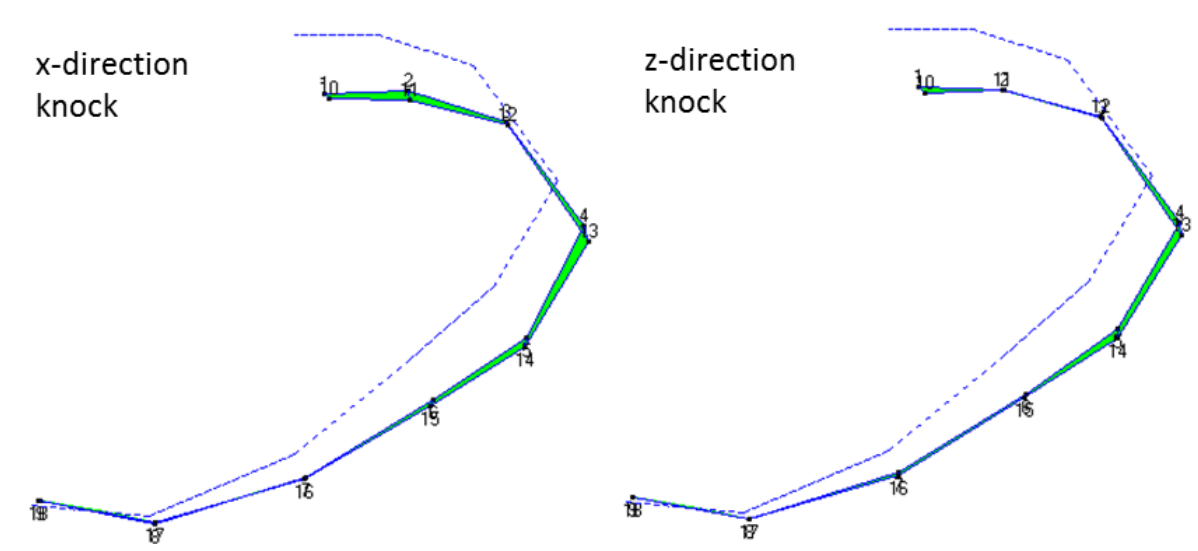

Figure S8: First bending mode of $8 \mathrm{LO}$ at $5.21 \mathrm{~Hz}$ and $5.22 \mathrm{~Hz}$ with free-free boundary condition knocked in $\mathrm{X}$ and $\mathrm{Z}$-direction respectively 


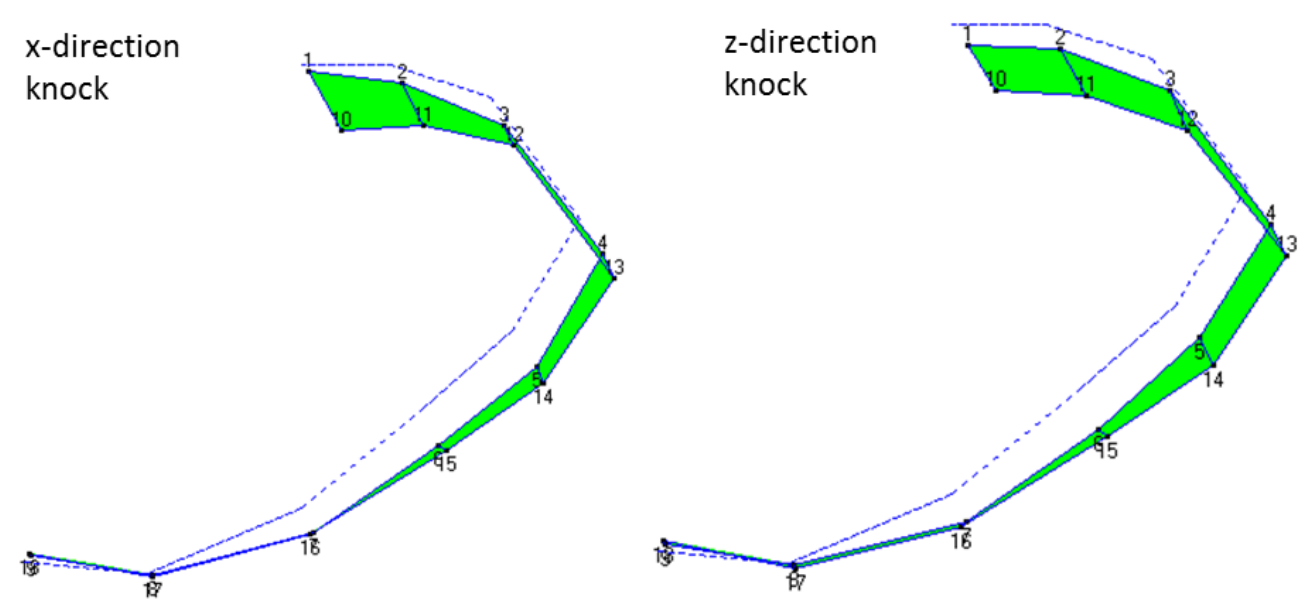

Figure S9: First bending mode of $9 \mathrm{LO}$ at $5.29 \mathrm{~Hz}$ and $5.33 \mathrm{~Hz}$ with free-free boundary condition knocked in $\mathrm{X}$ and $\mathrm{Z}$-direction respectively 